\title{
Carcinomas espinocelulares de boca invadindo o osso mandibular - qual a melhor técnica cirúrgica para a resseção parcial?
}

\author{
Van Gemert J, Irene Holtslag I, Van der Bilt A, Merkx M, Koole R, Van Cann E. Health-related quality \\ of life after segmental resection of the lateral mandible: Free fibula flap versus plate reconstruction. \\ Journal of Cranio-Maxillo-Facial Surgery. 2015; 43: 658-62.
}

TAISA MARIA RodRIGUes VILARDI (Doutoranda em patologia bucal (FOB-USP)

VITOR HUgo PARRA Graduando FOL - Unimep

O câncer é uma doença multifatorial que vem mostrando um aumento no número de casos nos últimos anos. Segundo os dados atuais apresentados pela Organização Mundial da Saúde (OMS), o tabagismo é o fator de risco mais importante, tendo sua ação potencializada quando associada ao etilismo. Ressalta-se, ainda, um aumento no risco de acordo com o tempo de uso, com o número de cigarros fumados por dia e com a frequência de ingestão de bebidas alcoólicas.

O carcinoma espinocelular (CEC) é a neoplasia maligna mais prevalente na cavidade bucal. Mesmo nos dias de hoje, o câncer de boca ainda possui um prognóstico relativamente pobre, com taxa de sobrevida em torno de cinco anos em menos de 50\% destes pacientes em virtude, principalmente, do diagnóstico tardio. Geralmente, estas lesões acabam invadindo o osso mandibular, tornando necessária a ressecção de um segmento. Este tipo de procedimento cirúrgico é o modo mais bem estabelecido na terapêutica definitiva inicial para o câncer, e este, sem dúvida, relacionado a uma diminuição na qualidade de vida dos indivíduos submetidos, podendo gerar riscos de lesões musculares, em nervos sensoriais e motores, consequentemente afetando a mastigação, deglutição e fala. Além disso, os pacientes também podem apresentar problemas estéticos, emocionais e sociais, refletindo de forma negativa na saúde e corroborando a baixa qualidade de vida. Para evitar maiores transtornos com aos indivíduos submetidos a estes tipos de tratamentos cirúrgicos, normalmente se opta pelas reconstruções imediatas de restauração da estética e reabilitação da função.

A escolha do tratamento deve ser cautelosa e valorizada, para que possa contribuir com o futuro bem-estar geral dos pacientes, pois envolve fatores associados ao tumor primário (como o estadiamento, sítio anatômico, histopatologia, tratamento prévio, envolvimento de linfonodos) e associados ao paciente (idade, condição médica geral, tolerância ao tratamento, estilo de vida, concordância com o tratamento), além de outros fatores envolvendo a situação socioeconômica e a equipe médica. De acordo com a OMS, a qualidade de vida não é somente a ausência de doença ou enfermidade, mas, também, a capacidade de um indivíduo levar a vida de uma forma produtiva e agradável.

Os transplantes defíbula, autólogos, são considerados uma opção mais completa para a reconstrução de mandíbulas parcialmente segmentadas em tratamentos cirúrgicos do câncer, pois é transplantado o tecido mole e o tecido ósseo, garantindo uma melhor função e estética, contribuindo com a saúde e qualidade de vida dos pacientes. Nestes casos, implantes 
dentários podem ser inseridos na mandíbula neoformada, para facilitar a reabilitação da oclusão. Porém, há algumas desvantagens na técnica, pois apresenta longo tempo de procedimento cirúrgico e requer um maior número de profissionais. Normalmente são duas equipes cirúrgicas trabalhando simultaneamente: uma para a ressecção da mandíbula com o preparo do local e outra para a coleta e preparo do fragmento de tecido mole e osso da fíbula. Além disso, o material obtido pode apresentar volume e altura de osso insuficientes para alcançar a reabilitação oclusal por um implante suportado por prótese, ou, ainda, a forma do osso transplantado pode não coincidir com o contorno original da mandíbula. Da mesma forma, o tecido mole obtido pode ser insatisfatório e requerer outra variedade de local doador. Assim, podemos observar que os transplantes de fíbula podem apresentar um maior risco de falhas.

Existe também outro método, bastante utilizado, para restaurar a continuidade da mandíbula. É realizado por meio do uso de placas de reconstrução convencionais. Esta técnica apresenta várias vantagens, além de ser segura e simples. Durante o ato cirúrgico, apenas uma equipe é suficiente para realizar todos os procedimentos, desde a ressecção parcial da mandíbula e preparo local até a colocação da placa de reconstrução. Mas riscos podem existir, como o de afrouxamento dos parafusos, a fratura da placa de reconstrução, a exposição da placa, infecção e formação de fístulas. Caso não exista qualquer tipo de complicação, as reconstruções por placa normalmente conduzem a bons resultados funcionais e estéticos. Embora o método cirúrgico de reconstrução da mandíbula com transplantes de fíbula seja considerado uma opção mais completa, ainda é desvantajoso quando comparado com o método cirúrgico da placa de reconstrução. As consequências de ambas as técnicas para a saúde e a qualidade de vida dos pacientes, independentemente da técnica, não apresentam influências significativas. Sendo assim, para que seja determinada a melhor técnica a ser utilizada, a escolha da reconstrução mandibular deve ser cuidadosamente discutida com o paciente, levando em conta o prognóstico e a expectativa de reabilitação dentária ou não. 